\title{
María José Villaverde Rico y Francisco Castilla Urbano (dirs.), La sombra de la leyenda negra, Madrid, Tecnos, 2016, 541 pp.
}

\section{Francisco Javier Espinosa Antón \\ Universidad de Castilla-La Mancha (España)}

La expresión "leyenda negra" apareció por primera vez en una conferencia de Emilia Pardo Bazán en 1899 y se popularizó a principios del siglo XX. Pero, ¿hubo una "leyenda negra"? ¿Cómo y por qué surgió? ¿Se puede hablar de «genocidio» para calificar la política colonizadora española en América? ¿Fue la política española igual, peor o mejor que la del resto de los países colonizadores europeos? ¿Por qué repunta la «leyenda negra» en el siglo XVIII, cuando en España empieza a extenderse la Ilustración y se impulsa la ciencia y el progreso? ¿Se puede hablar de racismo y de hispanofobia?

Catorce muy relevantes especialistas intentan dar respuesta a estas y otras preguntas. Y, como trabajan en diferentes disciplinas, dan una gran riqueza de variedad de enfoques y de ideas a la obra. Pero no se trata, como sucede frecuentemente, de una obra colectiva donde cada capítulo es independiente del resto, como un compartimento estanco. Aquí ha habido una planificación de la obra, que está concebida como una secuencia histórica, en la que primero se exponen los orígenes en los siglos XVI y XVII, luego su renacimiento en el siglo XVIII para acabar en el siglo XIX y en algunos aspectos del XX. Y también hay una intencionalidad para que la historia se trate desde diferentes puntos de vista: lo que escribían los autores extranjeros, cómo reaccionaban los autores españoles y como lo hicieron los hispanoamericanos. Y que es una obra articulada también se ve en que los autores conocen lo que han escrito los demás en los otros capítulos y frecuentemente dialogan entre sí y se citan. La extraordinaria riqueza e interés de la obra exige que su reseña sea amplia y más bien descriptiva, pues pretendo que el lector disponga de bastante información, para que esto le lleve a pensar que su lectura merece la pena.

Empieza con una gran (tanto en extensión como en calidad) introducción, "La leyenda negra: existencia, origen, recepción y reacciones", en la que los editores de la obra, María José Villaverde (catedrática de Ciencia Política de la universidad Complutense de Madrid y estudiosa de la imagen que ofrecen los ilustrados franceses de los amerindios, España y su colonización) y Francisco 
Castilla (profesor titular de Filosofía en la universidad de Alcalá e investigador de la conquista y la colonización de las Américas) hacen una especie de estudio general del tema, que sirve además de marco para ir presentando las diferentes contribuciones de los capítulos del libro.

Exponen las dos posiciones básicas en el tema. Para unos no habría una "leyenda negra". Las críticas a España serían algo normal dentro de los flujos de opinión crítica entre los países europeos. Todas las naciones habrían sufrido campañas de desprestigio por aquellos otros países que estaban interesados en conseguir su poder o sus riquezas. Aunque distorsionasen algo la realidad, esos relatos y juicios tendrían una cierta base en la historia, por lo que piensan que no se trataría de una hostilidad deliberada a lo largo del tiempo, aunque algunos tópicos exagerados pervivieran. Se suele decir, en esta línea de pensamiento, que lo específico del caso español es la relevancia que los propios españoles atribuyeron a estas críticas, fruto de un cierto complejo de inseguridad: la "leyenda negra" sería así el reflejo de un reflejo, una imagen doblemente deformada. Además, se añade, la "leyenda negra" incluso para algunos políticos, como Franco, llegaría a ser un arma del nacionalismo español para fortalecer una idea específica de identidad frente a las críticas extranjeras.

Para otros, nos señalan los editores, no se podría negar la existencia de la leyenda negra, a la que califican de injusta, falsa y muy dañina. Para ellos lo propio de la leyenda negra es que partiendo de algunas verdades se extiende la descalificación a todo un pueblo a lo largo de toda su historia. Sería precisamente esta mirada del otro la que influiría decisivamente en la construcción de una identidad española de baja autoestima. El complejo de inseguridad de los españoles sería el efecto y no la causa. La verdad es que la mirada del otro es esencial para construir la propia personalidad y, como decía, Rawls, el reconocimiento es un bien primario, objeto de la justicia. Subrayan, además, que las campañas de desprestigio de España tenían tintes racistas sobre el "ser" de los españoles: al fin y al cabo durante siglos en España habían estado los judíos y los moros.

Los editores, en esta magna introducción, trazan a grandes rasgos la historia de la leyenda negra, que surgió de la supremacía española y de los rencores que suscitó su poder militar, su expansión territorial, su influencia diplomática, su hegemonía monetaria y su dominio cultural. Además la incorporación de España a la vida política europea se produjo en un periodo muy corto de tiempo (50 años), lo que produjo mayor conmoción. Los orígenes se remontan a la mala prensa de los aragoneses y catalanes en el sur de Italia; esta mala imagen, ya aplicada a toda España, se consolida en el inicio siglo XVI en Italia debido a su fuerza militar. A pesar del establecimiento en la península hispánica de los estatutos de limpieza de sangre, empieza a extenderse la idea de un pueblo 
de raza inferior y de ortodoxia dudosa: ¿qué se podía esperar de esa raza degenerada de judíos, árabes musulmanes y moros?

Los conflictos entre católicos y protestantes y el papel de España fueron una nueva ocasión para renovar y acrecentar la leyenda negra. Un segundo hito importante en el origen de la "leyenda negra" está, pues, en los Países Bajos: las ejecuciones del Duque de Alba y las luchas de religión son decisivas. En este sentido, señalan los editores, no hay dudas de que en su origen la leyenda negra y la Reforma protestante son inseparables. Las grandes obsesiones de los holandeses eran Felipe II, el Duque de Alba y la Inquisición. Pero no está muy claro que la política española se pusiera totalmente al servicio de la confesión católica, indican, pues parece que a veces fue más bien una política pragmática. Un documento clave de este segundo momento fue la Apología de Guillermo de Orange de 1581. En esta obra ya aparece la crítica a España, además, por un tercer motivo: el comportamiento cruel en América.

Quizá el comportamiento de los españoles en América, en principio, no fue ni mejor ni peor que el de holandeses, ingleses y franceses, sostienen los editores. Es verdad que sobre todo en los primeros tiempos se cometieron muchos crímenes perpetrados por aventureros sin moral. Pero de ninguna manera se puede decir que hubiera una voluntad de exterminio y de genocidio, pues la mayoría de las muertes fue por causa de epidemias para las que no estaban protegidos los indios por su aislamiento. Si fuera verdad la tesis del exterminio, teniendo en cuenta las cifras computadas de los españoles que viajaron a Ámerica durante los primeros 50 años y las cifras de mortalidad de las que algunos hablan, todos españoles, también los clérigos, mujeres y niños, deberían haber matado al menos un indio diariamente y tres los domingos durante 50 años, recuerdan los editores. La verdad es que las críticas a España por su comportamiento en América tienen su origen en obras de españoles: la gran sensibilidad por los indios de algunos y una actitud receptiva de los políticos españoles, lo que se puede ver en la promulgación de una legislación precisamente de protección de los derechos de los indios (Leyes de Burgos de 1512 y de Valladolid de 1513 y las Leyes Nuevas de 1542), se convirtió irónica y paradójicamente en material inflamable para la crítica de España. Así fue especialmente con la obra de Las Casas Brevísima relación de la destrucción de las Indias publicada en 1552, que nació de una intención de ser un instrumento para proteger a los indios. De ella se harían muchas ediciones manipuladas y con ilustraciones tendenciosas en Holanda e Inglaterra para aprovecharlas como arma arrojadiza contra España

El tercer momento de la leyenda negra es el renacimiento de las críticas por parte principalmente de los ilustrados franceses, especialmente de Montesquieu, Voltaire, Raynal y Diderot. Quizá vieran en el espejo de España el lado oscuro en el que podía caer Francia y se dedicaron a cargar sin ecuanimidad contra 
la imagen de España. Aquí se achacaba especialmente a España por parte de los ilustrados franceses su fanatismo religioso, la Inquisición (que aunque no fue especialmente mortífera en comparación con algunas llamaradas de intolerancia, que se produjeron en otros países, como la misma Francia), la falta de libertades, la ausencia de progreso científico y de comercio, junto con la política colonial española en América. La obra clave fue la Historia de las dos Indias de Raynal/Diderot de 1770.

A finales del siglo XVIII, siguen narrando los editores, se da en España una especie de reacción frente a la leyenda negra. Se empieza a escribir otras historias de sus empresas coloniales: los jesuitas expulsos de América serán los encargados de elaborar historias apologéticas de España. Además hubo en ese tiempo un intento de ponerse a la par de las naciones europeas en los planos científico y económico, pero no hubo mucha continuidad en estos esfuerzos.

Como conclusión a su presentación, los editores del libro sí piensan que ha habido un enseñamiento especial contra España y una discriminación de orden ideológico o incluso racial. El problema surge cuando se pasa de criticar hechos puntuales, que podrían haber dado lugar a una propaganda anti-española circunscrita en el tiempo, a unas afirmaciones sobre el carácter nacional español a lo largo de los siglos (el español como un ser cruel, codicioso, ocioso, fanático, inculto...). Y, sobre todo, que muchos relatos críticos de las acciones españolas culminan con una referencia al tema de la raza impura, contaminada de moros y judíos, junto con la mención a la localización geográfica, que la separa de Europa y la acerca a África.

En el primer capítulo, "Argumentos hispanos para la construcción de la «leyenda negra» (Siglos XVI-XVII)" Francisco Castilla trata de aquellos escritos hispanos que luego se utilizarían contra España. Prototipo de ello es la obra de Las Casas, cuyo objetivo era cambiar la política y el comportamiento español en América. Ya en su tiempo algunos escritores españoles, aunque reconocían fallos en el comportamiento de los españoles, destacaron sus excesos y que podía ser utilizada contra España. En los finales del XVI y en el XVII hay una serie de pensadores que intentan reformar la marcha de España, los arbitristas, y critican lo que piensan que es el origen de su decadencia: la afluencia del oro, el abandono de las artes y oficios, la falta de comercio... Estas críticas también se añadirían posteriormente a la leyenda negra en la Ilustración, sin que se pueda determinar con precisión su grado de influencia, señala el autor, y dotarían a las críticas allí vertidas de un cierto grado credibilidad por ser en los propios españoles en los que se basaban.

El capítulo 2, titulado «"Un leopardo no puede cambiar sus manchas": la leyenda negra en los Países Bajos» de Yolanda Rodríguez Pérez (profesora titular de Estudios Europeos en la Universidad de Ámsterdam, especialista en imagología y en hispanofobia e hispanofilia), trata de la leyenda negra en 
Holanda, fundamentalmente en los siglos XVI y XVII, utilizando para ello no sólo los tradicionales instrumentos propagandísticos como panfletos o crónicas de guerra, sino también obras de teatro, novelas, composiciones poéticas... Además de tratar la Apología de Guillermo de Orange, la autora hace especial hincapié a la utilización que hicieron algunos holandeses de la obra de Las Casas, adaptándola para construir los famosos Espejos de la Juventud, utilizados para la enseñanza escolar para recordar a los jóvenes la inclinación a la crueldad de los españoles. El título del capítulo alude a un significativo texto de uno de ellos: "como un leopardo no puede borrar sus manchas, como un hombre moro no puede cambiar en blanco el color de su piel, así un español no puede cambiar su carácter sanguinario".

En el capítulo 3, "La leyenda negra en la nueva Inglaterra colonial (siglos XVII y XVIII)" de Alicia Mayer (directora del Centro de Estudios Mexicanos de la UNAM en España y que trabaja en los discursos colonizadores y las visiones del indio en la Nueva Inglaterra del siglo XVII), se muestra el manejo intelectual que hicieron los puritanos de Nueva Inglaterra de la leyenda negra en los siglos XVII y XVIII. Fue muy importante en la conformación del nuevo país. La campaña de descrédito moral contra España e Hispanoamérica se convirtió en un tópico común que además se utilizó para arremeter contra el catolicismo intransigente y supersticioso que había invadido Hispanoamérica. Incluso, según la autora, se podría pensar que estas críticas sirvieron también de algún modo como una cortina de humo para encubrir la codicia por las riquezas del Nuevo Mundo que ellos mismos también experimentaban.

En el capítulo 4, "La Historia de las dos indias y el resurgir de la leyenda negra en el siglo XVIII", de María José Villaverde, se analizan algunos de los documentos que en el siglo XVIII contribuyeron a la imagen negativa de España. Fundamentalmente se dedica a relatar y a describir la Historia de las dos Indias (primera edición de 1770 y tercera de 1780), una obra que fue un bestseller en la época de la Ilustración. Se trataba de un trabajo muy complejo, en el que participaron quizá 6 o 7 personas en su confección. La parte de Raynal, que en la tercera edición aparece como el autor, era crítica pero un tanto conservadora. La parte de Diderot, en cambio, era muy radical contra el colonialismo y el esclavismo. Curiosamente, señala la autora, en la parte de Raynal se ve tibieza frente al esclavismo y unos ciertos tintes racistas al hablar de los amerindios, mientras que la parte de Diderot es antirracista, amén de antiesclavista, por lo que atribuye la decadencia de España a factores políticos, económicos y religiosos que, al no estar inscritos en la naturaleza indeleble del carácter español, dejan abierta la posibilidad de cambios. La Historia de las dos Indias contribuyó como ningún otro libro en el XVIII a difundir la leyenda negra, señala la autora, contraponiendo los modelos de conquista y colonización de Inglaterra-Holanda con los de España. Se narra también en este 
capítulo cómo en España se hicieron intentos de difundir la Historia de las dos Indias, pero expurgada y depurada.

Jonathan Israel (Professor en el Institute for Advanced Study de Princeton y especialista en historia europea), en el capítulo 5, "La leyenda negra y la polémica de los ilustrados sobre los pueblos de la América española", trata fundamentalmente de las reacciones que provocó la Historia de las dos Indias en España (también en Hispanoamérica, donde fue vista como mejor base para la ideología independentista que las obras de Robertson y De Pauw que, aunque criticaban a España, estaban llenas de racismo y de prejuicios sobre la inferioridad natural de los habitantes de América). Para construir un relato ilustrado moderado y crítico frente al de la Historia de las dos Indias, al mismo tiempo que apológético de España, hubo tres estrategias, según el autor. Juan Nuix, del que trata abundantemente el capítulo, escribió sus Reflexiones en 1780 para defender a España y al mismo tiempo el pensamiento conservador. Con otro plan, el de construir una historia basada en documentos, cuya recopilación daría origen al Archivo Real de Indias, Juan Bautista Muñoz escribió su Historia del Nuevo Mundo, pero sólo pudo publicar un volumen en 1793 de su proyectada obra. Otra táctica diferente fue la del duque de Almodóvar, consistente en traducirla expurgándola, pero sólo se publicaron los primeros volúmenes.

En el capítulo 6, "La historiografía de los jesuitas desterrados y la «leyenda negra»sobre Hispanoamérica" de Victor Ruiz Peralta (historiador del CSIC que ha trabajado sobre el poder indiano en la España del XVIII y la historiografía de los jesuitas), también relata una historia de la reacción española en el siglo XVIII: las obras americanistas de los jesuitas peninsulares y americanos desterrados en Italia. Empieza hablando de la obra de Juan Nuix y su traducción al castellano. Luego trata de la obra de los jesuitas americanos Clavijero, Molina y Velasco, empresa que no acabó bien, lo que para el autor era una muestra clara de que la administración española no confiaba en el americanismo para rebatir las diatribas contra la colonización española. Por último narra la historia del jesuita peruano Viscardo que, después de algunos desencuentros con las autoridades españolas por su herencia, se puso bajo la protección de los británicos para escribir obras alentando a la separación de España.

En el capítulo 7, "William Robertson y la conquista española de América. Causalidad histórica y ausencia de leyenda negra" de Gerardo López Sastre (profesor titular de Filosofía de la Universidad de Castilla-La Mancha y especialista en la Ilustración escocesa y en W. Robertson), se valora la Historia de América de 1777 del historiador escocés William Robertson en el sentido de que de ninguna manera contribuyó a la leyenda negra ni en su examen de la conquista ni en su descripción de la evangelización. Señala 
que en la concepción de Robertson hay una especie de lógica histórica que hace que, independientemente de la acción de algunos agentes históricos, el sometimiento y la desaparición de los indios aparezca como inevitable, dada su inferioridad y la inobjetabilidad del proyecto civilizador europeo. Robertson habría interpretado los problemas en la colonización de Hispanoamérica, según el autor, como el resultado de una tensión entre la política protectora de la Corona española, de la que habla bien, y la avidez de los colonos, que traban a los indios como esclavos. En el fondo Robertson, indica el autor, plantea el problema de si es posible un verdadero diálogo intercultural cuando el grado de desarrollo de las sociedades que interactúan es tan diferente.

El capítulo 8, "La defensa crítico apologética de Juan B. Muñoz ante la leyenda negra ilustrada" de Fermín del Pino Díaz (antropólogo investigador del CSIC, especialista en historia de la antropología colonial y en los discursos e imágenes americanas en los siglos XVI-XIX), se dedica por entero a la obra de Juan B. Muñoz, especialmente a su obra Historia del Nuevo Mundo de 1793. Según el autor, Juan Bautista Muñoz quiso emular la famosa History of America de Robertson. Por eso su obra no sería una mera apologética, sino una historia basada en documentos, a cuya recopilación de colecciones dispersas por toda España dedicó una gran parte de su vida. Pero al final, recelos y maniobras hicieron que sólo se publicase un volumen de los ocho proyectados. También subraya, frente a algunos críticos, que Juan Bautista Muñoz mostró interés por los pueblos americanos y fue sensible al arte nativo. En resumen, señala, la obra de Juan B. Muñoz supuso elevar un escalón más el nivel de la producción cultural frente a las críticas extranjeras.

Anthony Pagden (Distinguished Professor de Ciencia Política e Historia de la universidad de Los Ángeles y que ha estudiado las relaciones entre Europa y sus colonias), en el capítulo 9, "Espíritu de conquista. La leyenda negra y la transformación del mundo iberoamericano", afirma que la leyenda negra habría sido un medio de negar validez moral al poder militar expansionista de España. Con el tiempo, las críticas a la intolerancia religiosa, la crueldad y la rapacidad (que en mayor o menor medida compartían las otras potencias europeas) fueron ampliamente compartidas por muchos españoles: había que dejar de lado el espíritu de conquista, la leyenda dorada y heroica de la España de inicios de la Modernidad, para crear una sociedad comercial más abierta y libre, así como para tratar a los hispanoamericanos como iguales. Algunos, como Aranda, cuenta, propusieron un sistema federal entre España y tres reinos hispanoamericanos (correspondientes a los tres virreinatos), pero para Bolívar y otros, esas propuestas llegaron tarde porque la igualdad solo vendría de la mano de la independencia.

John C. Laursen (Professor de Ciencia Política de la universidad de Riverside, que estudia la visión de España y los encuentros entre indios y 
europeos en la Alta California) y Ricardo Crespo (Associate In de Ciencia Política de la misma universidad, que investiga las relaciones ente indígenas, americanos, ingleses y españoles en la Alta California) en el capítulo 10, "La leyenda negra en la costa norte del Pacífico", señalan que la leyenda negra fue a menudo más bien un instrumento al servicio de polémicas internas en el ámbito de la política española y que dado que California estaba tan lejos y era tan insignificante para la metrópoli, los españoles no tuvieron ocasión de proyectar allí una leyenda negra. Además en la costa norte del Pacífico no se mencionaba a Las Casas, Raynal o Diderot, lo que hace pensar que allí no hubo leyenda negra, amén de que en conjunto la actitud y la política de las autoridades españoles hacia los nativos no daban motivos para una leyenda negra sobre una especial crueldad.

En el capítulo 11, "Del peso del aire y las disciplinas invisibles. La polémica de la ciencia española como narrativa de una modernidad elusiva", de Juan Pimentel (científico titular de Historia de la Ciencia en el CSIC y que investiga las relaciones entre ciencia, lenguaje político, literatura de viajes y cultura visual en la Edad Moderna), se trata la relación entre la leyenda negra y la polémica de la ciencia española. En 1782 Masson de Morvilliers en un artículo en la Encyclopédie méthodique se preguntaba si Europa debía algo a España, lo que fue el detonante para la pregunta de si había contribuido en algo a la ciencia. Según el autor del capítulo, habría que notar que gran parte de la actividad científica española de la Ilustración tenía por objeto a América, precisamente el escenario en el que se habían fraguado los episodios centrales de la leyenda negra. Recuerda la obra de Jorge Juan y Antonio de Ulloa, así como la de Martín Fernández de Navarrete, la de Jovellanos o la del italiano Malaspina al servicio de la corona española. Pero para el autor, lo cierto que es la invisibilidad es uno de los rasgos de la ciencia española, de ahí la pregunta y la polémica. Y para él, en lugar de preguntarnos sobre si en España hubo ciencia o no, o si fue más o menos ilustrada, sería más productivo preguntarnos por qué nos hacemos con tanta frecuencia esa pregunta o a qué fines sirven los relatos de la excentricidad española o de su modernidad escurridiza e invisible.

En el capítulo 12, "La leyenda negra, las independencias y las nuevas naciones latinoamericanas", de Tomás Pérez Vejo (Profesor-Investigador en la Escuela Nacional de Antropología e Historia de México y estudioso de la imagen de España en la configuración nacional hispanoamericana), se nos narra cómo los líderes de la independencia en Hispanoamérica utilizaron las fuentes de la leyenda negra, fundamentalmente las obras de Las Casas y de Raynal, para deslegitimar el dominio de la corona española e incluir su lucha en el movimiento ilustrado de la emancipación de la humanidad. Pero estos líderes, representantes de las élites criollas, tuvieron que cambiar, no sin dificultad, la retórica: de reivindicarse descendientes de los conquistadores, exigiendo los 
mismos derechos que los peninsulares, a mostrarse como descendientes de los conquistados, que habían sido cruelmente maltratados por España durante 300 años. Así, según el autor, pudo parecer que la destrucción de las Indias era una obra de "ellos" y no de "nosotros". Además la leyenda negra siguió jugando durante un tiempo un cierto papel, mucho más en los políticos liberales hispanoamericanos que en los conservadores, utilizando una cierta idealización del mundo prehispánico. Luego irá decayendo su uso en la segunda mitad del siglo XIX. Posteriormente se inició, según el autor, un segundo uso de la leyenda negra en los indigenismos de la segunda mitad del siglo XX.

En el capítulo 13, “«Los desaciertos de nuestros padres». Los liberales y la eclosión del llamado «problema español»", de Javier Fernández Sebastián (catedrático de Historia del Pensamiento Político en la universidad de País Vasco, que trabaja en historia de conceptos relevantes en el mundo iberoamericano en los siglos XVIII-XIX), se explora, en una serie de políticos y escritores públicos ilustrados, liberales y progresistas desde finales del siglo XVIII hasta bien entrado el XIX, el despuntar de una nueva conciencia histórica fuertemente crítica para con el pasado español y muy receptiva hacia algunos de los tópicos característicos de la leyenda negra. Un momento fundamental, indica el autor, son los dos periodos absolutistas fernandinos que proporcionaron el caldo de cultivo para el relanzamiento de muchos temas de la leyenda negra. Se utilizaron los temas de la leyenda negra provenientes de medios protestantes europeos (fanatismo religioso en España, monarquía católica, ignorancia científica, ausencia de comercio...) para el debate político contra los conservadores. Y se pensaba que el origen de la debilidad económica, científica, comercial e internacional de España radicaba en la larga Reconquista que había generado hábitos guerreros e intolerantes. Y les resultaba difícil reconciliar a estos pensadores liberales, dice el autor, su crítica del pasado con un mínimo de lealtad a la tradición nacional, especialmente al apogeo cultural español de los siglos XVI y XVII. Estas dificultades ayudaron a crear un género literario sobre "el ser de España". Algunos elaboraron maniqueamente una contraposición entre una larga tradición de libertades, que iba desde los comuneros, pasando por los judíos expulsados, los alumbrados, los moriscos, los liberales, los progresistas, hasta los republicanos, y la tradición de la España intolerante e inquisitorial. Estas elaboraciones, carentes de sentido histórico, recalca el autor, se hicieron populares y coincidieron con el manido retrato de las "dos Españas".

José Álvarez Junco (catedrático de Historia del Pensamiento Político y los Movimientos Políticos y Sociales y que ha estudiado las visiones de España y la construcción de su identidad), en el capítulo 14, "De la leyenda negra a la leyenda romántica", trata del cambio de imagen de España en el siglo XIX. Las guerras napoleónicas y los viajes hicieron que mucha gente visitase 
España. Además el romanticismo con su fascinación por el pasado medieval y el culto a las pasiones originó que muchos europeos vieran a España como el país auténtico. El capítulo trata especialmente a 4 autores que contribuyeron a cambiar la imagen de España: Humboldt, Byron, Irving y Víctor Hugo. A partir de aquí, según el autor, se desarrollaron dos líneas en la construcción de la imagen romántica de España. Para académicos anglosajones del XIX España era el atraso, pero al mismo tiempo algo "pintoresco". Para los viajeros románticos, que venían a España con ideas preconcebidas, ésta era algo exótico, peligroso, premoderno y oriental. Se había puesto de moda como objeto de un viaje aventurero de gente con alma de artista. Pero el romanticismo no introdujo cambios sustanciales en la descripción del país, pues seguía siendo visto como un país atrasado; lo que estaba cambiando era la valoración: se reinterpretaron los temas de la leyenda negra para presentarlos en términos más positivos. También el romanticismo penetró en los escritores españoles y trataron los mismos temas, aunque, como en general eran liberales y respiraban el progreso, no pretendían que la pasión, el peligro, lo exótico o lo oriental fuera la esencia de la identidad nacional.

La calidad de cada uno de los capítulos del libro es incuestionable, pues se recurre siempre a una gran abundancia de fuentes, que el lector puede seguir en las notas. Además esas fuentes son interpretadas con perspicacia y razonabilidad. Al final de la lectura queda una muy rica y variada imagen de la leyenda negra, lo que es necesario, dado que es un asunto de una enorme complejidad. Pero al mismo tiempo también queda un hilo conductor para su interpretación y comprensión, con lo que se evita uno de los principales problemas de este tipo de obras, que los árboles no dejen ver el bosque. 